\title{
Simultaneous optimization of drilling responses using GRA on Al-6063/TiC composite
}

\author{
P. Venkateshwar Reddy ${ }^{1,3}$ - P. Ramanjaneyulu ${ }^{2,5} \cdot$ B. Veerabhadra Reddy ${ }^{3}$ P. Srinivasa Rao ${ }^{4}$
}

Received: 20 December 2019 / Accepted: 7 February 2020 / Published online: 18 February 2020

(c) Springer Nature Switzerland AG 2020

\begin{abstract}
The aim of the current work is to optimize the drilling constraints simultaneously during drilling of an Al6063/TiC composite based on grey relational analysis. Drilling trials were performed on Al-6063 reinforced with $15 \mathrm{wt} \%$ titanium carbide (TiC) of size $50 \mu \mathrm{m}$. HSS twist drills with diameter of $10 \mathrm{~mm}$ under lubricated condition were utilized for performing drilling tests. Drilling parameters explicitly helix angle, spindle speed, feed rate and responses such as surface roughness, cutting force and temperature are considered in the study. Grey relational grades were calculated to find the optimum levels of parameters, and moreover major involvement of constraints was dogged by ANOVA. The drilled composite specimen surface was analyzed under scanning electron microscopy (SEM). SEM metaphors of the drilled composite face specified the charisma of grooves, micro-cracks and dents.
\end{abstract}

Keywords MMCs· Drilling · GRA · ANOVA · Optimization

\section{Introduction}

Ceramic-reinforced metal matrix composites (MMCs) are highly capable materials for many functions with a combination of various desirable properties. MMCs possess the blend of contradicting properties of the base material (metallic alloys) and the ceramics. Thus, they have high toughness; lightweight-high strength and modulii, combinations of better properties of both [1,2]. Thus, reinforcements usually improve the properties of base material. Demand for better, advanced and improved materials in the fields like automobile and aerospace industries led to a rapid development of MMCs [3, 4]. Waku and Nagasawa [5] found that monolithic materials are inferior to MMCs in many facets. Methods to fabricate ceramics and MMCs are discussed by Rosso [6]. Numerous methods are developed for manufacturing MMCs. Stir casting is regarded as an accepted method because of its unique features. Several metals and their alloys have been used as matrix in the research works for producing MMCs. The most worked on material is aluminum and its admixtures [7-9]. Many research studies suggested the suitability of Al-based composites for structural applications. Uvaraja and Natarajan [10] have conducted experiments on the hardness of Al-7075 alloy with $\mathrm{B}_{4} \mathrm{C}$ kept as constant at $3 \mathrm{wt} \%$ and $w \mathrm{t} \%$ of $\mathrm{SiC}$ varying between 0 and 15 . The highest hardness for the composite was obtained at wt\% for $\mathrm{SiC}$ at 15 . Composites with $\mathrm{SiC}$ and flyash reinforced with aluminum and hybrid composite with aluminum $\mathrm{SiC}$ and flyash were experimentally investigated by Boopathi et al. [11] for the determination their hardness. It was proven that the hybrid composite with $10 \%$ of both $\mathrm{SiC}$ and fly ash has been the hardest when compared to $\mathrm{Al}-\mathrm{SiC}$ and $\mathrm{Al}$-fly ash composites.

P.Venkateshwar Reddy, mr.pvreddy@gmail.com; P. Ramanjaneyulu, dearram68@gmail.com; rama@iiitk.ac.in; B.Veerabhadra Reddy, veerabhadra.basam@gmail.com; P. Srinivasa Rao, er.p.srinivas@gmail.com | ${ }^{1}$ Department of Mechanical Engineering, JNT University (GPREC Research Centre), Ananthapuramu, A.P., India. ${ }^{2}$ Department of Mechanical Engineering, SV University, Tirupathi, A.P., India. ${ }^{3}$ Department of Mechanical Engineering, G Pulla Reddy Engineering College, Kurnool, A.P., India. ${ }^{4}$ Department of Mechanical Engineering, Vardhaman College of Engineering, Shamshabad, Telangana, India. ${ }^{5}$ Department of Mechanical Engineering, IIITDM-Kurnool, Kurnool, A.P., India. 
AA 5052 reinforced with different volume proportions of $\mathrm{ZrB}_{2}$ particles were studied by Kumar et al. [12]. From the study, it was observed by the author that there is an improvement in mechanical properties because of the formation of $\mathrm{ZrB}_{2}$ particles. Hardness improved continuously with $\mathrm{ZrB}_{2}$ content. whereas tensile properties enlarged up to 9 vol\% $\mathrm{ZrB}_{2}$. Fracture behavior of the $\mathrm{Al} 7075 / \mathrm{SiC}$ composite was studied by Kalkanli and Yilmaz [13] using the threepoint bend test. It was observed that flexural strength and reinforcement in wt $\%$ of $\mathrm{SiC}$ were directly related till a wt $\%$ of 10 , where the flexural strength was reported to be $580 \mathrm{MPa}$. From the wt $\%$ of 10 till wt $\%$ of 30 , the above parameters were observed to be inversely related. At wt $\%$ of 30 , flexural strength was observed to be $300 \mathrm{MPa}$. Sliding wear tests have been employed by Suresh [14] to investigate the wear of Al-based MMCs reinforced with particles of $\mathrm{B}_{4} \mathrm{C} \mathrm{SiC}$, $\mathrm{TiC}$ and TiB2. The tests were conducted for $80 \mathrm{~N}$ and $160 \mathrm{~N}$ loading using a pin-on-disc apparatus. The wear rate for the above Al-MMC is observed to be lower than that for the pure Al. Negligible influence of reinforcement size and type was noticed on the wear rate. But volume has a marginal consequence on wear rate.

Reinforcement particles present in the MMCs make the tools blunt and wear the tools with reduction in tool life. Most of the hard tools like carbide and HSS reduce their tool life while machining MMCs as explained by Aramesh et al. [15] in their work. Challenging on machining of MMCs increased due to the presence and development of hard reinforcements day by day. So far, most of the developed MMCs are machined using the conventional methods like turning, drilling, milling etc. keeping the cost aspects into the consideration. But high abrasive wear of tools are observed by the conventional machining methods, which again results to higher cost addition with poor machinability. Optimizing the machining parameters is required improve the machinability of the composites. Most of the researchers concluded that PCD tools are better suitable tools for machining the composite materials than the HSS and carbide tools as explained in the literature [16-18]. Munia raj and Manoharan [19] investigated the torque produced during drilling of the aluminum-based MMC with $15 \mathrm{wt} \% \mathrm{SiC}$ and wt $\%$ graphite as reinforcements. The work concluded that the feed rate is the highly influenced factor to control the torque during the drilling of MMCs. From the work, it was also concluded that spindle speed is the least influencing factor during dry drilling of MMCs.

From the exceeding works, it is examined that assessment of mechanical properties and the machining of
MMCs reinforced with $\mathrm{SiC}, \mathrm{TiC}$ and $\mathrm{Al}_{2} \mathrm{O}_{3}$ were carried out, but only few researchers concentrated on the machining of MMCs with such reinforcements. From the literature, it was also understood that the factors like weight fraction of reinforcements along with its distribution and properties of the matrix affect the machining of MMCs highly. The present study is aimed to expose the optimum drilling parameters of Al-6063 matrix reinforced with TiC composites. In order to determine the effects of drilling parameters on the surface roughness, cutting force and drilling temperature, three different helix angle, spindle speed and feed rate were used. The experimental consequences were interpreted by the help of GRA and ANOVA for the simultaneous optimization and influence of drilling parameters on responses. The most effective drilling parameters on machinability characteristics of MMCs were determined.

\section{Materials and methods}

This section presents the details of the materials and methods used to investigate the machining parameters effect on the MMCs. The mechanical as well as machinability properties of the MMCs depend on the ceramic (TiC) wt $\%$ used in the composite sample.

\subsection{Work piece material}

The composite used in the study was Al- 6063 with 15 wt $\%$ of TiC MMC which were made up by the liquid processing technique with a thickness of $10 \mathrm{~mm}$. The reinforcement $w t \%$ used in the current study was based on the previous study of the author [20]. The base metal Al-6063 aluminum alloys chemical composition is tabulated in Table 1. The stir casting setup is shown in Fig. 1. Table 2 shows the physical and its mechanical properties of Al-6063/TiC composites [20].

\subsection{Drilling of composite}

Drilling tests were performed under soluble oil (1:10) as a lubricant on Al-6063 with $15 \mathrm{wt} \%$ TiC-reinforced composites using a Universal drilling machine (GPREC Kurnool, A.P., India). In the current work, three controlling factors (helix angle, spindle speed and feed rate) with three levels each and HSS drill bits with a diameter of $10 \mathrm{~mm}$ have been considered. The composite tested for drilling is having a length of $160 \mathrm{~mm}$ and $60 \mathrm{~mm}$
Table 1 Chemical composition of matrix material (Al-6063) aluminum alloy

\section{SN Applied Sciences}

\begin{tabular}{lllllllllll}
\hline Elements & $\mathrm{Al}$ & $\mathrm{Fe}$ & $\mathrm{Si}$ & $\mathrm{Cu}$ & $\mathrm{Mg}$ & $\mathrm{Mn}$ & $\mathrm{Cr}$ & $\mathrm{Ti}$ & $\mathrm{Zn}$ & Others \\
\hline Composition (wt\%) & 97.5 & 0.35 & 0.60 & 0.1 & 0.9 & 0.1 & 0.1 & 0.1 & 0.1 & 0.15 \\
\hline
\end{tabular}




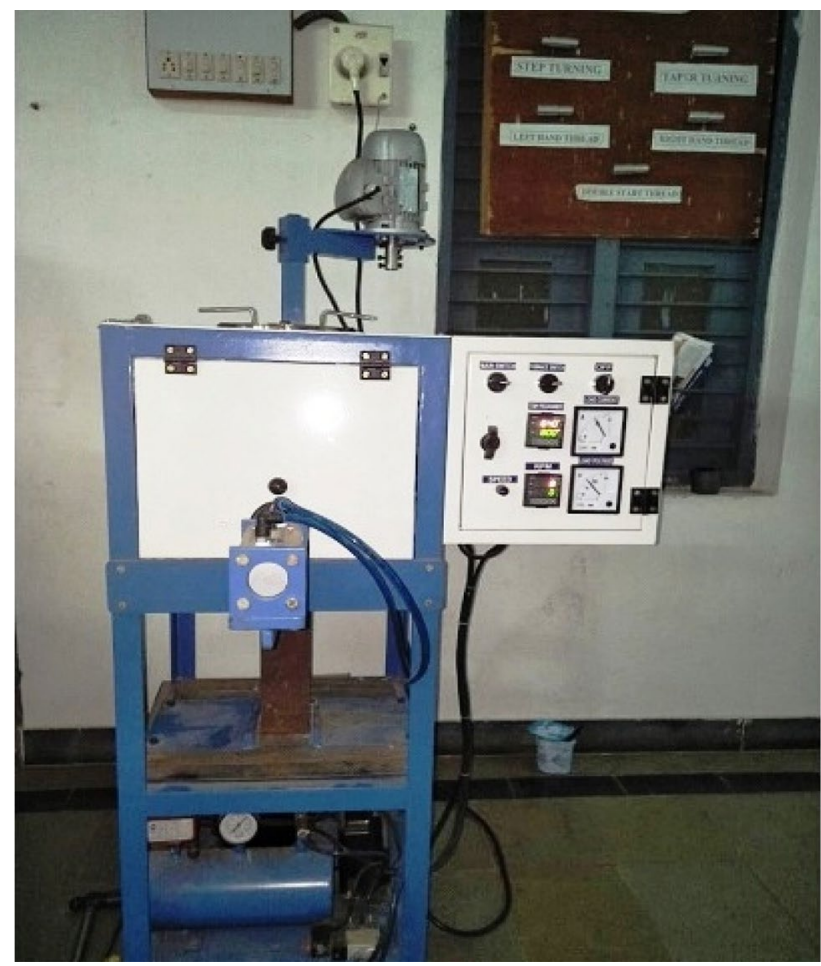

Fig. 1 Stir casting setup

Table 2 Physical and tensile properties of composites with different reinforcement content [20]

\begin{tabular}{lllll}
\hline $\begin{array}{l}\text { Sample designa- } \\
\text { tion }\end{array}$ & $\begin{array}{l}\text { Density } \\
(\mathrm{g} / \mathrm{cc})\end{array}$ & $\begin{array}{l}\text { Microhardness } \\
(\mathrm{HV})\end{array}$ & $\begin{array}{l}\text { UTS } \\
(\mathrm{MPa})\end{array}$ & $\begin{array}{l}\text { Elongation } \\
(\%)\end{array}$ \\
\hline $\begin{array}{l}\text { Al } 6063+5 \text { wt\% } \\
\quad \text { TiC }\end{array}$ & 2.81 & 59.6 & 127 & 9 \\
$\begin{array}{l}\text { Al } 6063+10 \text { wt\% } \% \\
\quad 2.86\end{array}$ & 73.8 & 132 & 7 \\
$\quad \begin{array}{l}\text { AlC } 6063+15 \text { wt\% } \\
\text { TiC }\end{array}$ & 2.93 & 99.6 & 144 & 5 \\
\end{tabular}

width with a constant thickness of $10 \mathrm{~mm}$. Full factorial design was considered for performing the drilling experiments. Experimental test setup with dynamometer and used drill bits are shown in Fig. 2. The dynamometer connected to the drilling machine was an armed wheel strain gauge type which is capable of measuring both thrust force and torque during the drilling of composite specimens. Considered constraints and their ranks are listed in Table 3. Responses like cutting force were deliberated using a dynamometer, and surface roughness by a Talysurf roughness tester. Drilling tool-work interface temperature was examined using a pyrometer.

\section{Results and discussion}

The main purpose of the work is to optimize the drilling parameters simultaneously to achieve lower surface roughness (SR), cutting force (CF) and temperature (Temp.) in the drilling of the TiC-reinforced Al-6063 MMC. The drilled specimen with various test conditions is shown in Fig. 3. Experimental run conditions and its corresponding responses are tabulated in Table 4.

It is observed from Table 4 that increase in helix angle improved the surface roughness. This is due to the fact that surface flaws and irregularities get smeared out by raising helix angle at the drilling region. Similar results were observed by other peers who are working in the similar area [21, 22]. Higher helix angle decreases the temperature at the tool, which can be observed by Table 4. Increase in feed rate increased the surface roughness and cutting force similar to others researches $[23,24]$. Enhance in feed rate decreased the temperature slightly during drilling of AMMC under the lubricated condition. Lower feed rate develops higher temperatures; thereby, the decrease in shear strength of workpiece at the cutting region takes place and let effortless shearing of the composite specimen during drilling.

\subsection{Grey relational analysis procedure}

Grey relational study is a way of converting two or more output parameters into a single output parameter so as to change the multi-response problem into a singleresponse one [25]. The method of grey relational study is explained in the subsections $[26,27]$.

\subsubsection{Normalization of the test results}

The experimental response values for punch force, thinning ratio and dome height have to be normalized in the range from 0 to 1 using Eqs. 1 and 2 .

The normalized value for the larger the better type of response is

$Z_{i}(\mathrm{~K})=\frac{Y_{i}(k)-\min Y_{i}(k)}{\max Y_{i}(k)-\min Y_{i}(k)}$

The normalized value for the smaller the better type of response is

$Z_{i}(\mathrm{~K})=\frac{\max Y_{i}(k)-Y_{i}(k)}{\max Y_{i}(k)-\min Y_{i}(k)}$

$Z_{i}(\mathrm{~K})$ is the normalizing value. 

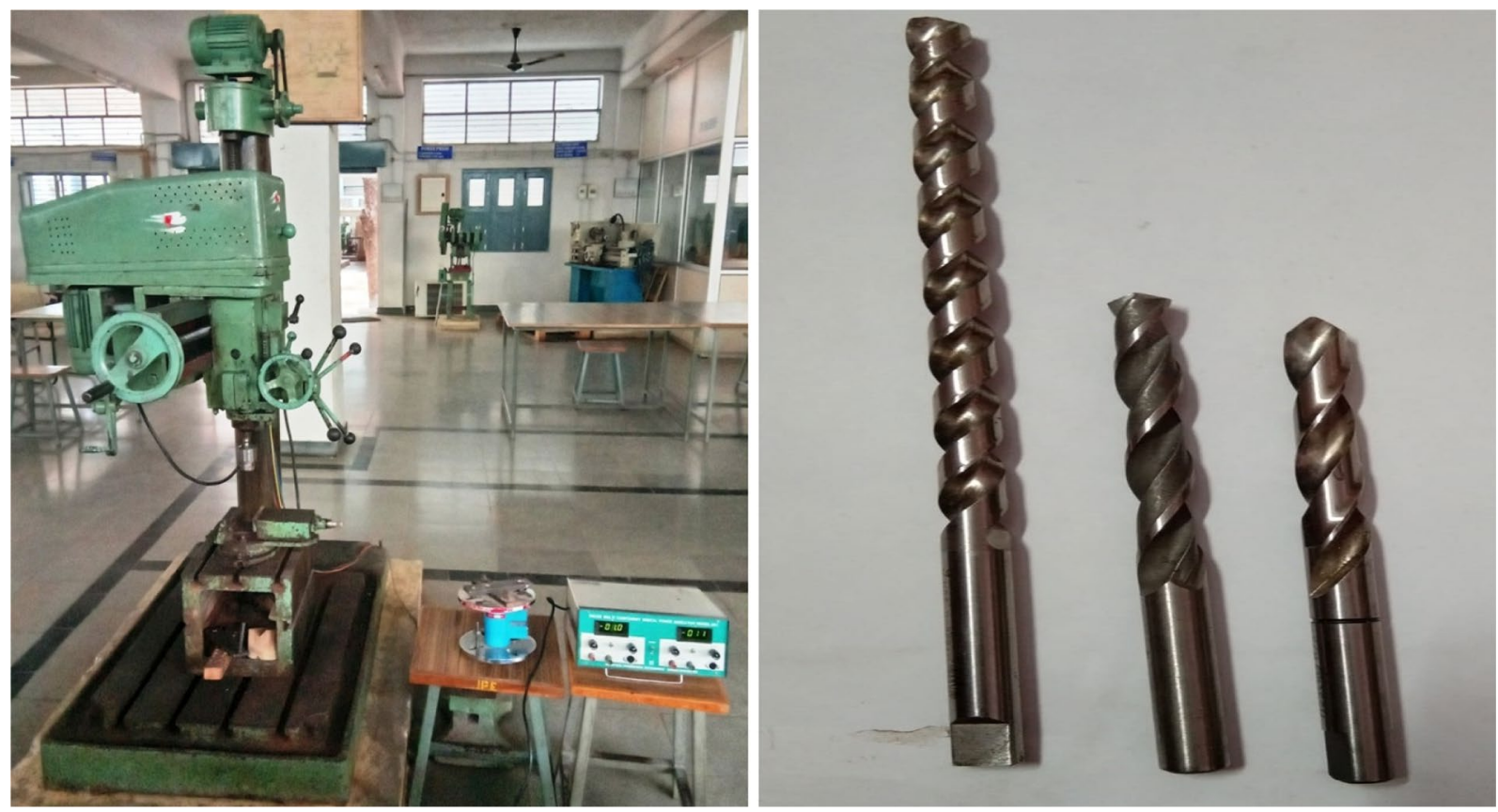

Fig. 2 Experimental test setup with dynamometer and drill bits

Table 3 Process parameters and its levels considered in the work

\begin{tabular}{llllll}
\hline Factors & Parameters & Units & Level 1 & Level 2 & Level 3 \\
\hline A & Helix angle & degrees & 20 & 30 & 40 \\
B & Spindle speed & RPM & 400 & 500 & 600 \\
C & Feed rate & mm/rev & 0.1 & 0.2 & 0.3 \\
\hline
\end{tabular}

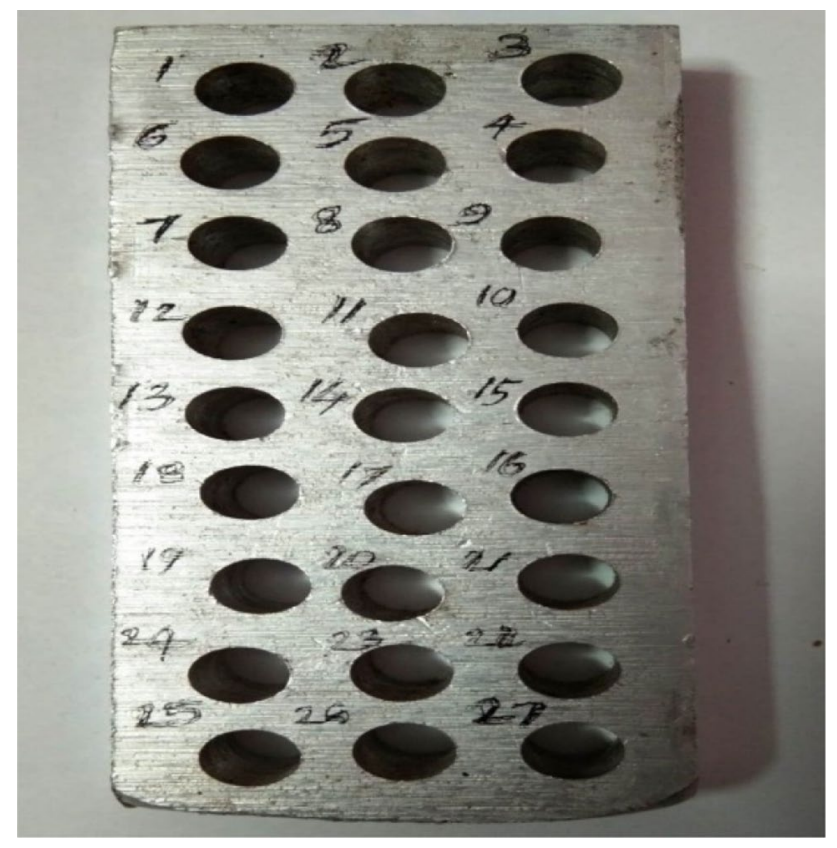

\subsubsection{Grey relation coefficient (GRC)}

The grey relational coefficient values were calculated by Eq. 3.

$\varepsilon_{i}(\mathrm{~K})=\frac{\Delta_{\min }+\varphi \Delta_{\max }}{\Delta_{o i}(K)+\varphi \Delta_{\max }}$

where $\Delta_{o i}$ is the quality loss function $=\Delta_{o i}(\mathrm{~K})=\left(Z_{o}(\mathrm{~K})-Z_{i}\right.$ (K)) and $\Delta_{\min }$ and $\Delta_{\max }$ are the min. and max. values of the differences of $\Delta_{o i}$. The distinguish coefficient can be accustomed by the choice maker to exercise the judgment, and various distinguish coefficients produce various results in GRA. Based on the best results obtained in the literature, the distinguishing coefficient was set as 0.5 initially in the present work. The value of $\varphi$ lies between 0 and 1 and is taken preferably to be 0.5 since all the responses are given equal importance.

\subsubsection{Grey relation grade (GRG) and order}

The grey relation coefficients shown in Table 5 are averaged in order to obtain the grey relation grade. By calculating the grey relational grades using Eq. 4, the multiple reactions are converted into single reactions.

Grey relation grade $\left(\gamma_{i}\right)=\frac{1}{n} \sum_{k=1}^{n} \varepsilon_{i}(\mathrm{~K})$

Fig. 3 MMC after drilling holes at various test conditions 
Table 4 Experimental run conditions and their responses

\begin{tabular}{|c|c|c|c|c|c|c|}
\hline Test no. & Helix angle $\left(^{\circ}\right)$ & $\begin{array}{l}\text { Spindle } \\
\text { speed (rpm) }\end{array}$ & $\begin{array}{l}\text { Feed rate } \\
(\mathrm{mm} / \mathrm{rev})\end{array}$ & $\begin{array}{l}\text { Surface } \\
\text { roughness } \\
(\mu \mathrm{m})\end{array}$ & Cutting force (N) & $\begin{array}{l}\text { Tempera- } \\
\text { ture }\left({ }^{\circ} \mathrm{C}\right)\end{array}$ \\
\hline 1 & 20 & 450 & 0.1 & 0.426 & 570.78 & 29.5 \\
\hline 2 & 30 & 450 & 0.1 & 0.567 & 470 & 29.3 \\
\hline 3 & 40 & 450 & 0.1 & 0.263 & 422.22 & 28.3 \\
\hline 4 & 20 & 450 & 0.2 & 0.54 & 653.78 & 29.4 \\
\hline 5 & 30 & 450 & 0.2 & 0.66 & 435.78 & 29.0 \\
\hline 6 & 40 & 450 & 0.2 & 0.39 & 454 & 28.7 \\
\hline 7 & 20 & 450 & 0.3 & 0.806 & 774.78 & 29.2 \\
\hline 8 & 30 & 450 & 0.3 & 0.953 & 553.78 & 29.6 \\
\hline 9 & 40 & 450 & 0.3 & 0.463 & 535.78 & 28.9 \\
\hline 10 & 20 & 500 & 0.1 & 0.416 & 525.75 & 29.0 \\
\hline 11 & 30 & 500 & 0.1 & 0.48 & 411 & 29.2 \\
\hline 12 & 40 & 500 & 0.1 & 0.203 & 392.22 & 28.7 \\
\hline 13 & 20 & 500 & 0.2 & 0.426 & 653.78 & 29.3 \\
\hline 14 & 30 & 500 & 0.2 & 0.643 & 435.78 & 29.3 \\
\hline 15 & 40 & 500 & 0.2 & 0.273 & 414 & 28.9 \\
\hline 16 & 20 & 500 & 0.3 & 0.656 & 653.78 & 30.0 \\
\hline 17 & 30 & 500 & 0.3 & 0.853 & 544.89 & 29.7 \\
\hline 18 & 40 & 500 & 0.3 & 0.326 & 490.21 & 28.8 \\
\hline 19 & 20 & 560 & 0.1 & 0.38 & 530.78 & 30.2 \\
\hline 20 & 30 & 560 & 0.1 & 0.47 & 424 & 29.6 \\
\hline 21 & 40 & 560 & 0.1 & 0.193 & 392.22 & 29.0 \\
\hline 22 & 20 & 560 & 0.2 & 0.43 & 658.78 & 31.7 \\
\hline 23 & 30 & 560 & 0.2 & 0.51 & 435.78 & 29.7 \\
\hline 24 & 40 & 560 & 0.2 & 0.256 & 414 & 29.8 \\
\hline 25 & 20 & 560 & 0.3 & 0.53 & 721.78 & 33.9 \\
\hline 26 & 30 & 560 & 0.3 & 0.56 & 573.78 & 31.9 \\
\hline 27 & 40 & 560 & 0.3 & 0.256 & 544.89 & 29.8 \\
\hline
\end{tabular}

where $n$ is the no. of responses and $\varepsilon_{i}(\mathrm{~K})$ is the grey relation coefficient. Grey relational grades along with their rank (1st rank for the largest GRG) are shown in Table 5.

Here, by means of "grey relational analysis," various responses are united to solo response, i.e., GRG, for tone down in optimization. Three drilling parameters are considered for optimizing and also three responses, i.e., surface roughness (SR), cutting force (CF) and tool temperature (Temp.) simultaneously. The procedure for the computation of GRG is talked about in Sect. 3.1. The experimental test results in Table 4 are utilized for calculating the normalized SR, CF and Temp., which are shown in Table 5 . The calculated normalized value by Eq. 2 is used to work out GRCs for all the three outcomes using Eq. (3). Later, GRG is estimated from GRCs for all the experimental results using Eq. (4). As per the GRG conventions, the test conditions are correlated with 'higher is better policy' [28]. The optimal value, highest GRG, was originated to be the 12 th experimental test condition, and the corresponding test set can be observed in
Table 4. By maximizing the grade values (Table 5), minimum SR, CF and Temp. can be simultaneously obtained at the helix angle of $40^{\circ}$, spindle speed of $500 \mathrm{rpm}$ and feed of $0.1 \mathrm{~mm} / \mathrm{rev}$ optimal drilling conditions. Figure 4 represents the main effects plots of GRG. From Fig. 4, similar results are observed as grey relational analysis, i.e., high helix angle, medium speed and lower feed for better GRG. Increase in spindle speed and feed leads to the increase in drilling temperature. This also led to an increase in adverse effect on the cutting edge; thereby, wear and burning scars around the drilling area increase. Increase in helix angle increases the cutting edge such that the reduction in chip thickness and chip width. Meanwhile thrust force decreases by this increase in helix angle. Lower helix angle had an adverse effect on wear of the composite sample (workpiece) during the drilling operation; in other words, higher helix angle also induces less wear of drill bit also. Higher spindle speed and feed rate impart higher wear of the drill bit and cutting edge angle. 
Table 5 Estimated grey relational grades and their rankings

\begin{tabular}{|c|c|c|c|c|c|c|c|c|c|}
\hline \multirow[t]{2}{*}{ Test no. } & \multicolumn{3}{|c|}{ Normalized } & \multicolumn{3}{|c|}{$\begin{array}{l}\text { Grey relational coef- } \\
\text { ficient }\end{array}$} & \multirow[t]{2}{*}{ GRG (Expt.) } & \multirow[t]{2}{*}{ GRG predicted } & \multirow[t]{2}{*}{$\begin{array}{l}\text { Rankings of } \\
\text { GRG (Expt.) }\end{array}$} \\
\hline & SR & CF & Temp. & SR & CF & Temp. & & & \\
\hline 1 & 0.69 & 0.53 & 0.79 & 0.62 & 0.52 & 0.70 & 0.612 & 0.63300 & 18 \\
\hline 2 & 0.51 & 0.80 & 0.82 & 0.50 & 0.71 & 0.74 & 0.651 & 0.76390 & 16 \\
\hline 3 & 0.91 & 0.92 & 1.00 & 0.84 & 0.86 & 1.00 & 0.903 & 0.89480 & 3 \\
\hline 4 & 0.54 & 0.32 & 0.80 & 0.52 & 0.42 & 0.72 & 0.554 & 0.53530 & 20 \\
\hline 5 & 0.39 & 0.89 & 0.88 & 0.45 & 0.81 & 0.80 & 0.688 & 0.66620 & 11 \\
\hline 6 & 0.74 & 0.84 & 0.93 & 0.66 & 0.76 & 0.88 & 0.763 & 0.79710 & 6 \\
\hline 7 & 0.19 & 0.00 & 0.84 & 0.38 & 0.33 & 0.76 & 0.491 & 0.43760 & 25 \\
\hline 8 & 0.00 & 0.58 & 0.77 & 0.33 & 0.54 & 0.68 & 0.519 & 0.56850 & 22 \\
\hline 9 & 0.64 & 0.62 & 0.89 & 0.58 & 0.57 & 0.82 & 0.660 & 0.69940 & 15 \\
\hline 10 & 0.71 & 0.65 & 0.88 & 0.63 & 0.59 & 0.80 & 0.673 & 0.63010 & 13 \\
\hline 11 & 0.62 & 0.95 & 0.84 & 0.57 & 0.91 & 0.76 & 0.746 & 0.76100 & 8 \\
\hline 12 & 0.99 & 1.00 & 0.93 & 0.97 & 1.00 & 0.88 & 0.950 & 0.89190 & 1 \\
\hline 13 & 0.69 & 0.32 & 0.82 & 0.62 & 0.42 & 0.74 & 0.593 & 0.53240 & 19 \\
\hline 14 & 0.41 & 0.89 & 0.82 & 0.46 & 0.81 & 0.74 & 0.670 & 0.66330 & 14 \\
\hline 15 & 0.89 & 0.94 & 0.89 & 0.83 & 0.90 & 0.82 & 0.849 & 0.79420 & 4 \\
\hline 16 & 0.39 & 0.32 & 0.70 & 0.45 & 0.42 & 0.62 & 0.498 & 0.43470 & 23 \\
\hline 17 & 0.13 & 0.60 & 0.75 & 0.37 & 0.56 & 0.67 & 0.529 & 0.56560 & 21 \\
\hline 18 & 0.83 & 0.74 & 0.91 & 0.74 & 0.66 & 0.85 & 0.750 & 0.69650 & 7 \\
\hline 19 & 0.75 & 0.64 & 0.66 & 0.67 & 0.58 & 0.60 & 0.615 & 0.62662 & 17 \\
\hline 20 & 0.64 & 0.92 & 0.77 & 0.58 & 0.86 & 0.68 & 0.706 & 0.75752 & 9 \\
\hline 21 & 1.00 & 1.00 & 0.88 & 1.00 & 1.00 & 0.80 & 0.933 & 0.88842 & 2 \\
\hline 22 & 0.69 & 0.30 & 0.39 & 0.62 & 0.42 & 0.45 & 0.495 & 0.52892 & 24 \\
\hline 23 & 0.58 & 0.89 & 0.75 & 0.55 & 0.81 & 0.67 & 0.675 & 0.65982 & 12 \\
\hline 24 & 0.92 & 0.94 & 0.73 & 0.86 & 0.90 & 0.65 & 0.802 & 0.79072 & 5 \\
\hline 25 & 0.56 & 0.14 & 0.00 & 0.53 & 0.37 & 0.33 & 0.410 & 0.43122 & 27 \\
\hline 26 & 0.52 & 0.53 & 0.36 & 0.51 & 0.51 & 0.44 & 0.486 & 0.56212 & 26 \\
\hline 27 & 0.92 & 0.60 & 0.73 & 0.86 & 0.56 & 0.65 & 0.688 & 0.69302 & 10 \\
\hline
\end{tabular}

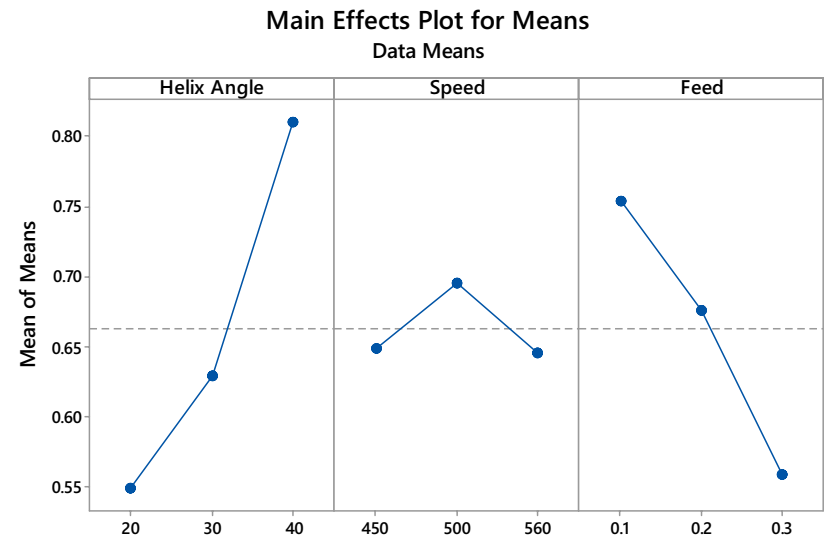

Fig. 4 Main effect plot for GRG

\subsection{ANOVA for GRG}

The implication and percentage convince of process parameters over the worth and individuality was found out by performing analysis of variance (ANOVA) [29-31]. Table 6 shows the ANOVA results of GRG. Based on the contribution entitlement, the most highly influenced feature for drilling operation is helix angle of the drilling tool with $63.2 \%$ contribution and feed rate with $34.02 \%$ contribution. Speed is not influencing parameter for drilling the $\mathrm{Al}-6063 / \mathrm{TiC}$ composites. Similar results in line with the present results were observed in the literature as well [32]. The drilling of composite specimen with higher helix angle generates less cutting force and cutting temperature due to the increase in flute volume for emigration of chips and temperature distribution [33]. The decrease in helix angle leads to the increase in the cutting length edge such that cutting edge increases. Increase in helix angle leads to the decrease in undeformed chip height and width so that the cutting edge decreases during the drilling operation. 
Table 6 ANOVA of GRG

\begin{tabular}{lllllll}
\hline Source & DF & Adj SS & Adj MS & F-value & $P$-value & \% Contribution \\
\hline Helix angle & 2 & 0.32360 & 0.161801 & 135.10 & 0.000 & 63.2 \\
Spindle speed & 2 & 0.01391 & 0.006955 & 5.81 & 0.010 & 2.78 \\
Feed rate & 2 & 0.17407 & 0.087036 & 72.67 & 0.000 & 34.02 \\
Error & 20 & 0.02395 & 0.001198 & & & \\
Total & 26 & 0.53554 & & & \\
Model summary & & & & & \\
$S$ & $R$-sq & $R$-sq(adj) & $R$-sq(pred) & & \\
0.0346064 & $95.53 \%$ & $94.19 \%$ & $91.85 \%$ & & & \\
\hline
\end{tabular}

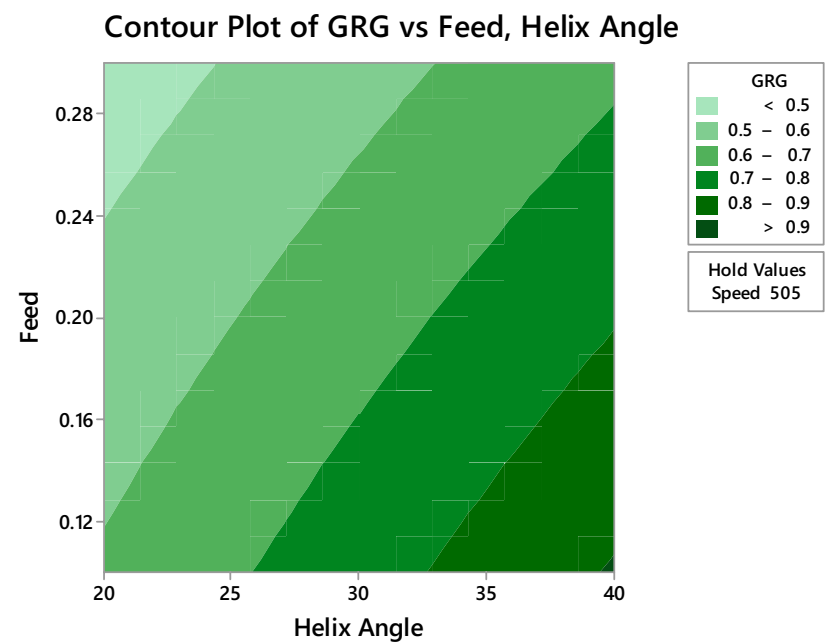

Fig. 5 Contour plot of GRG versus feed and helix angle

\subsection{Regression analysis}

Correlation between independent, dependent and unknown parameters can be made possible with the help of regression analysis. An Eq. 5 shows the regression model generated for the GRG using MiniTab-16. The regression equation can be used to predict the GRG values for various levels of process parameters within the lower and higher limits. The drilling parameters with $P$ value less than 0.05 indicated that the model terms significantly affected the response in the design space. Equation 5 indicates the relationship between the GRG and the drill process parameters, i.e., helix angle, spindle speed and feed rate. Figure 5 illustrates the contour plot of GRG for two highly influenced parameters (helix angle and feed rate) during the drilling of composite specimens which can be observed from Table 6. From Fig. 5, it is experiential that the increase in helix angle and the decrease in feed rate attained a higher GRG value at a steady speed of $505 \mathrm{rpm}$.
Interactions among the drilling parameters are not much influencing the response which is clearly observed from Table 6.

$$
\begin{aligned}
\mathrm{GRG}= & 0.495+0.01309 \text { Helix angle } \\
& -0.000058 \text { Spindle speed }-0.977 \text { Feed rate }
\end{aligned}
$$

Figure 6 illustrates the scatter plot of GRG with all the three considered drilling parameters. From Fig. 6 , it is clearly understood that GRG increased with the increase in helix angle and decreased with the increase in feed rate. The influence of the spindle speed on GRG is very small which can be observed in Fig. 6b. ANOVA of GRG (Table 6) specified the similar results that speed is the least influencing factor among the three considered drilling factors. Similar results like influence of feed is more in drilling the MMCs were observed by others researchers as well [34].

\subsection{Confirmation test}

The validation of the experimental test results was carried out by performing the confirmation test with three repetitions. The results obtained by the confirmation test are shown in Table 7, and the confirmation tested sample is shown in Fig. 7. The average values were utilized to validate the prediction of GRG.

The GRG calculated from confirmation experiments was 0.901 , whereas the GRG by experimental calculated value is 0.891 . The confirmation of the GRG is valid since the error value is less than $1 \%$.

\subsection{SEM analysis}

The drilled composite surface was observed by SEM to analyze the morphology of the machined surface. The SEM morphology of the drilled surface composite specimens is exposed in Fig. 8. Mostly in the drilling procedure, mutual rubbing of abrasive particles takes place, which 
a

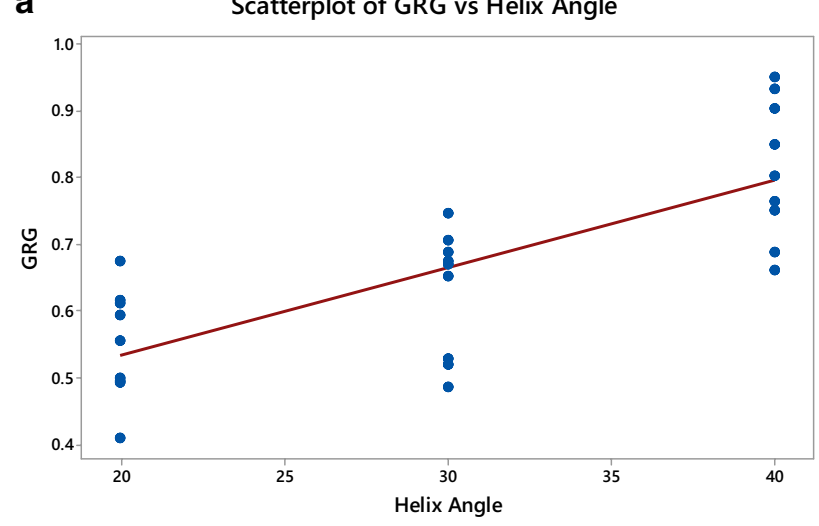

b

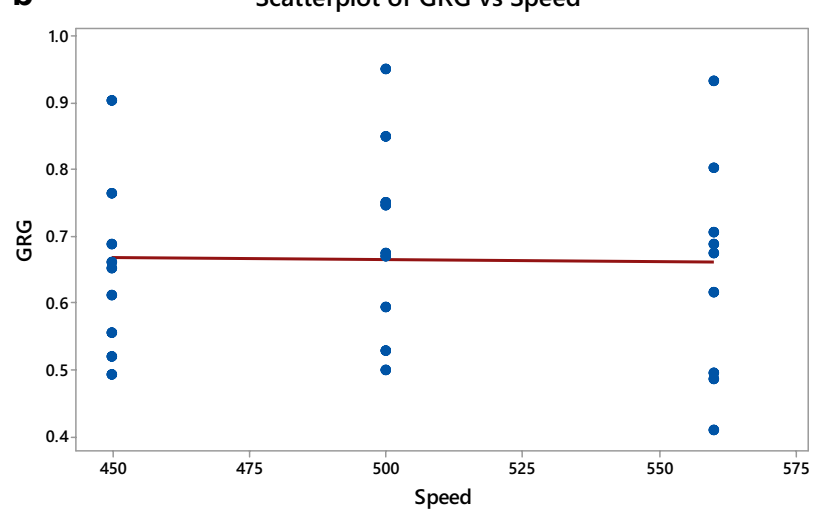

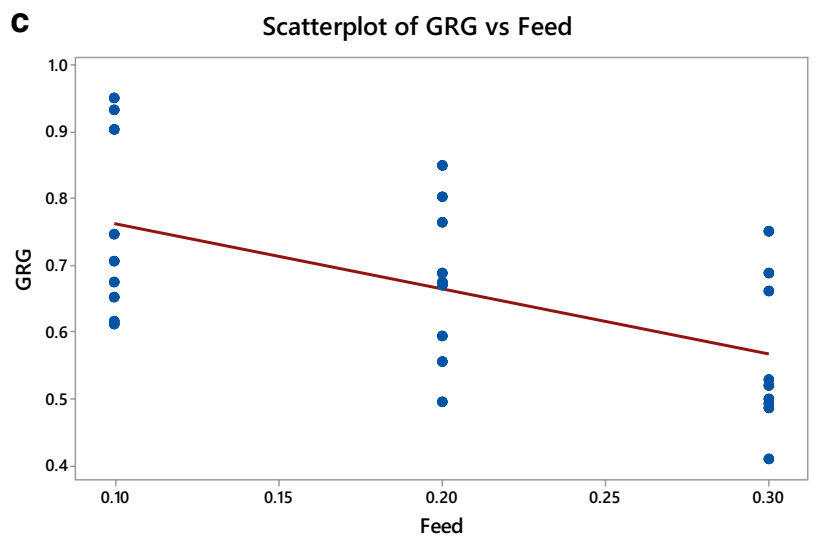

Fig. 6 Scatter plot a GRG versus helix angle, b GRG versus speed and c GRG versus feed

Table 7 Confirmation test results

\begin{tabular}{|c|c|c|c|c|c|c|}
\hline \multirow[t]{2}{*}{ S. no } & \multicolumn{3}{|c|}{ Drilling parameters } & \multicolumn{3}{|l|}{ Responses } \\
\hline & Helix angle $\left({ }^{\circ}\right)$ & $\begin{array}{l}\text { Spindle } \\
\text { speed (rpm) }\end{array}$ & $\begin{array}{l}\text { Feed rate } \\
\text { ( } \mathrm{mm} / \mathrm{rev})\end{array}$ & $\begin{array}{l}\text { Surface } \\
\text { roughness } \\
(\mu \mathrm{m})\end{array}$ & Cutting force $(\mathrm{N})$ & $\begin{array}{l}\text { Tempera- } \\
\text { ture }\left({ }^{\circ} \mathrm{C}\right)\end{array}$ \\
\hline 1 & 40 & 500 & 0.1 & 0.205 & 396.2 & 28.9 \\
\hline 2 & 40 & 500 & 0.1 & 0.202 & 392.1 & 28.5 \\
\hline 3 & 40 & 500 & 0.1 & 0.208 & 390.4 & 28.1 \\
\hline \multicolumn{4}{|c|}{ Average } & 0.205 & 392.9 & 28.5 \\
\hline
\end{tabular}

smoothens the surface of the composite. When compared to Fig. 8a and b, Fig. 8b shows smooth surface due to the higher helix angle with less feed rate. After thorough examination of the SEM images, morphology of the drilled surface reveals that a higher feed rate causes the wide surface dent in the composite specimens which may be because of higher contact pressure. Moreover, high feed rate increases the tool-workpiece interface can be observed from Table 4 as well. This leads the composite specimen soften due to plastic deformation. More pulling out of particles was observed in Fig. 8 a $\&$ b. The occurrence of the cracks on the machined surface is due to the strain hardening of the composite specimen. Enlarge in micro-cracks leads to the voids in the composites [35, 36] which is observed in Fig. 8a. Figure 8a shows lot of scratches because of more contact pressure due to elevated feed rate. Once the particles start pulling out from the composite specimens, crack and pits form over the surface which leads to the reduced surface finish of the drilled surface. 


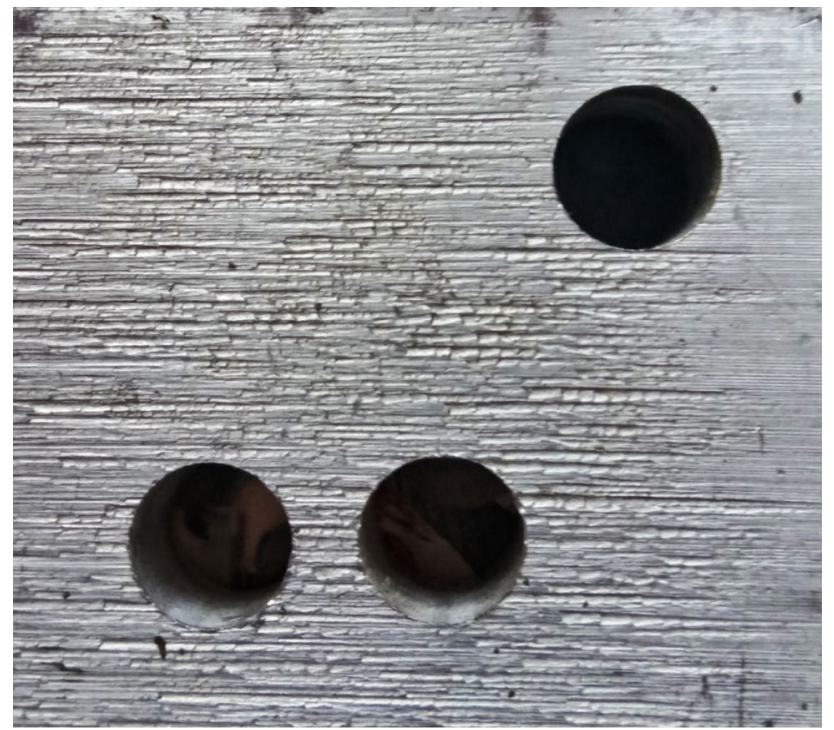

Fig. 7 Confirmation test composite sample

\section{Conclusion}

In this study, grey relational analysis was tailored to discover the cause of drilling parameters on fabricated aluminum Al-6063 reinforced with 15 wt\% TiC composites. A multi-objective function named full factorial design based grey relational analysis were tailored to get the optimal parameter setting of the drilling parameters, for minimizing the surface roughness, cutting force and tool temperature in drilling operation.
1. GRA is an extremely valuable procedure to optimize the SR, CF and Temp., during the drilling of aluminumbased MMCs since it does not entail several complex mathematical presumptions and simulation can be easily used by the practitioners or engineers in the industry.

2. In the present study, the optimal arrangement of drilling parameters identified by GRA is higher helix angle $\left(40^{\circ}\right)$, medium spindle speed (500 rpm) and lower feed $(0.1 \mathrm{~mm} / \mathrm{rev})$.

3. ANOVA of the GRG revealed that helix angle is the most influencing parameter with $63.2 \%$ contribution followed by feed with $34 \%$ contribution. Speed is the least contribution with $2.7 \%$ for optimizing the drilling parameters for drilling AMMC.

4. The SEM description of the drilled surface confirms the proof of honing result, debris and trimmed surface of the composite material.

Acknowledgements The authors would sincerely like to thank the management of G Pulla Reddy Engineering College (Autonomous), Kurnool, for providing the testing facilities and their constant support.

\section{Compliance with ethical standards}

Conflict of interest The authors declare that there is no conflict of interest regarding the publication of this paper.
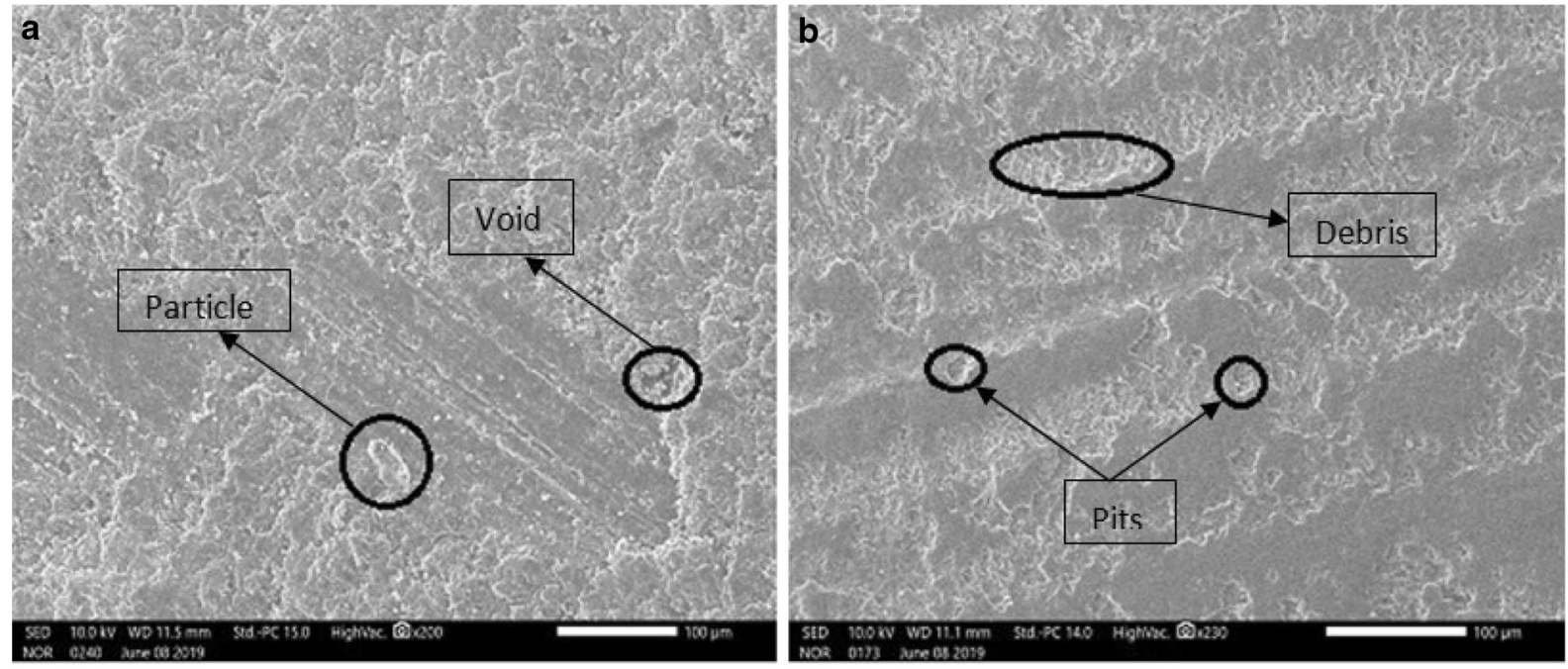

Fig. 8 SEM images of the drilled surface at speed of $500 \mathrm{rpm}$ with a helix angle 20 and feed rate 0.3 and $\mathbf{b}$ helix angle 40 and feed rate 0.1 


\section{References}

1. Nicholls CJ, Boswell B, Davies IJ, Islam MN (2017) Review of machining metal matrix composites. Int J Adv Manuf Technol 90(9-12):2429-2441

2. Singh J, Chauhan A (2016) Characterization of hybrid aluminum matrix composites for advanced applications - a review. J Mater Res Technol 5(2):159-169

3. Li J, Laghari RA (2019) A review on machining and optimization of particle-reinforced metal matrix composites. Int J Adv Manuf Technol 100(9-12):2929-2943

4. Koli DK, Agnihotri G, Purohit R (2015) Advanced aluminium matrix composites: the critical need of automotive and aerospace engineering fields. Mater Today Proc 2(4-5):3032-3041

5. Waku Y, Nagasawa T (1994) Future trends and recent developments of fabrication technology for advanced metal matrix composites. Mater Manuf Process 9(5):937-963

6. Rosso M (2006) Ceramic and metal matrix composites: routes and properties. J Mater Process Technol 175(1-3):364-375

7. Reddy PV, Kumar GS, Kumar VS, Reddy BV (2020) Effect of substituting $\mathrm{SiC}$ in varying proportions for $\mathrm{TiC}$ in $\mathrm{Al}-5052 / \mathrm{TiC} / \mathrm{SiC}$ hybrid MMC. J Bio Tribo Corros 6(1):1-11

8. Pakseresht AH, Baghbaderani HA, Yazdani-Rad R (2016) Role of different fractions of nano-size $\mathrm{SiC}$ and milling time on the microstructure and mechanical properties of $\mathrm{Al}-\mathrm{SiC}$ nanocomposites. Trans Indian Inst Met 69(5):1007-1014

9. Pathapalli VR, Basam VR, Gudimetta SK, Koppula MR (2019) Optimization of machining parameters using WASPAS and MOORA. World J Eng. https://doi.org/10.1108/WJE-07-2019-0202

10. Uvaraja VC, Natarajan N (2012) Optimization of friction and wear behaviour in hybrid metal matrix composites using Taguchi technique. J Miner Mater Charact Eng 11(08):757

11. Boopathi MM, Arulshri KP, lyandurai N (2013) Evaluation of mechanical properties of aluminium alloy 2024 reinforced with silicon carbide and fly ash hybrid metal matrix composites. Am J Appl Sci 10(3):219

12. Kumar N, Gautam RK, Mohan S (2015) In-situ development of ZrB2 particles and their effect on microstructure and mechanical properties of AA5052 metal-matrix composites. Mater Des 80:129-136

13. Kalkanlı A, Yılmaz S (2008) Synthesis and characterization of aluminum alloy 7075 reinforced with silicon carbide particulates. Mater Des 29(4):775-780

14. Suresh KR, Niranjan HB, Jebaraj PM, Chowdiah MP (2003) Tensile and wear properties of aluminum composites. Wear 255(1-6):638-642

15. Aramesh M, Attia MH, Kishawy HA, Balazinski M (2016) Estimating the remaining useful tool life of worn tools under different cutting parameters: a survival life analysis during turning of titanium metal matrix composites (Ti-MMCs). CIRP J Manuf Sci Technol 12:35-43

16. Xiang J, Xie L, Gao F, Yi J, Pang S, Wang X (2018) Diamond tools wear in drilling of $\mathrm{SiCp} / \mathrm{Al}$ matrix composites containing copper. Ceram Int 44(5):5341-5351

17. Basavarajappa $S$ (2009) Tool wear in turning of graphitic hybrid metal matrix composites. Mater Manuf Process 24(4):484-487

18. Ismail SO, Dhakal HN, Dimla E, Popov I (2017) Recent advances in twist drill design for composite machining: a critical review. Proc Inst Mech Eng Part B J Eng Manuf 231(14):2527-2542

19. Raj AM, Manoharan N (2014) Experimental investigation and analysis of torque in drilling $\mathrm{Al}-15 \% \mathrm{SiC}-4 \%$ graphite metal matrix composites using response surface methodology. Indian J Sci Technol 7(S6):87-94
20. Reddy PV, Prasad PR, Krishnudu DM, Goud EV (2019) An investigation on mechanical and wear characteristics of Al 6063/TiC metal matrix composites using RSM. J Bio Tribo Corros 5(4):90

21. Balaji M, Murthy BSN, Rao NM (2016) Optimization of cutting parameters in drilling of AISI 304 stainless steel using Taguchi and ANOVA. Proc Technol 25:1106-1113

22. Navanth A, Sharma TK (2013) A study of taguchi method based optimization of drilling parameter in dry drilling of al 2014 alloy at low speeds. Int J Eng Sci Emerg Technol 6(1):65-75

23. Kumar D, Singh KK, Zitoune R (2016) Experimental investigation of delamination and surface roughness in the drilling of GFRP composite material with different drills. Adv Manuf Polymer Compos Sci 2(2):47-56

24. Tsao CC, Hocheng $\mathrm{H}$ (2008) Evaluation of thrust force and surface roughness in drilling composite material using Taguchi analysis and neural network. J Mater Process Technol 203(1-3):342-348

25. Selvarajan L, Narayanan CS, JeyaPaul R (2016) Optimization of EDM parameters on machining Si3N4-TiN composite for improving circularity, cylindricity, and perpendicularity. Mater Manuf Process 31(4):405-412

26. Chinnaiyan P, Jeevanantham A (2014) Multi-objective optimization of single point incremental sheet forming of AA5052 using Taguchi based grey relational analysis coupled with principal component analysis. Int J Precis Eng Manuf 15(11):2309-2316

27. Haq AN, Marimuthu P, Jeyapaul R (2008) Multi response optimization of machining parameters of drilling $\mathrm{Al} / \mathrm{SiC}$ metal matrix composite using grey relational analysis in the Taguchi method. Int J Adv Manuf Technol 37(3-4):250-255

28. Tosun N, Pihtili H (2010) Gray relational analysis of performance characteristics in MQL milling of 7075 Al alloy. Int J Adv Manuf Technol 46(5-8):509-515

29. Reddy PV, Reddy BV, Rao PSA (2018) Numerical study on tube hydroforming process to optimize the process parameters by Taguchi method. Mater Today Proc 5(11):25376-25381

30. Sankaraiah G, Kumar GS, Kumar VS, Reddy PV (2019) Experimental and comparative study on material effect of vortex tube on the cold outlet air temperature. In: AIP conference proceedings, vol 2161, no 1, p 020021. AIP Publishing, College Park

31. Reddy PV, Krishnudu DM, Pranavi U, Ramulu PJ (2019) Optimization of the forming parameters in U-bending for punch force and springback using Taguchi method. In: Advances in computational methods in manufacturing, pp 75-84. Springer, Singapore

32. Çiçek A, Kıvak T, Ekici E (2015) Optimization of drilling parameters using Taguchi technique and response surface methodology (RSM) in drilling of AISI 304 steel with cryogenically treated HSS drills. J Intell Manuf 26(2):295-305

33. Wika KK, Sharman AR, Goulbourne D, Ridgway K (2011) Impact of number of flutes and helix angle on tool performance and hole quality in drilling composite/titanium stacks (No. 2011-012744). SAE Technical Paper

34. Rajmohan T, Palanikumar K, Davim JP (2012) Analysis of surface integrity in drilling metal matrix and hybrid metal matrix composites. J Mater Sci Technol 28(8):761-768

35. El-Gallab M, Sklad M (1998) Machining of Al/SiC particulate metal matrix composites: part II: workpiece surface integrity. J Mater Process Technol 83(1-3):277-285

36. Rajmohan T, Palanikumar K (2013) Application of the central composite design in optimization of machining parameters in drilling hybrid metal matrix composites. Measurement 46(4):1470-1481

Publisher's Note Springer Nature remains neutral with regard to jurisdictional claims in published maps and institutional affiliations. 